\title{
The quality of feedback from outpatient departments at referral hospitals to the primary care providers in the Western Cape: a descriptive survey
} \author{
Germarie Fouche $^{b}$ and Dusica Stapar ${ }^{a, b}$ \\ ${ }^{a}$ Division of Family Medicine and Primary Care, Stellenbosch University, Cape Town, South Africa \\ ${ }^{b}$ Department of Health, Western Cape, South Africa \\ *Corresponding author, email: rm@sun.ac.za
}

Robert Mash $^{a *}$ (D) Herma Steyn ${ }^{b}$, Muideen Bello ${ }^{a, b}$, Klaus von Pressentin ${ }^{a, b}$ (D) Liezel Rossouw ${ }^{b}$, Gavin Hendricks ${ }^{a, b}$,

Background: Coordinating care for patients is a key characteristic of effective primary care. Family physicians in the Western Cape formed a research network to enable them to perform practical research on key questions from clinical practice. The initial question selected by the network focused on evaluating the quality of referrals to and feedback from outpatient departments at referral hospitals to primary care providers in the Western Cape.

Methods: A descriptive survey combined quantitative data collected from the medical records with quantitative and qualitative data collected from the patients by questionnaire. Family physicians collected data on consecutive patients who had attended outpatient appointments in the last three months. Data were analysed using the Statistical Package for the Social Sciences. Results: Seven family physicians submitted data on 141 patients ( $41 \%$ male, 59\% female; $46 \%$ metropolitan, $54 \%$ rural). Referrals were to district $(18 \%)$, regional $(28 \%)$ and tertiary hospitals $(51 \%)$. Referral letters were predominantly biomedical. Written feedback was available in $39 \%$ of patients. In $32 \%$ of patients, doctors spent time obtaining feedback; the patient was the main source of information in $53 \%$ of cases, although many patients did not know what the hospital doctor thought was wrong (36\%). The quality of referrals differed significantly by district and type of practitioner, while feedback differed significantly by level of hospital.

Conclusion: Primary care providers did not obtain reliable feedback on specialist consultations at referral hospital outpatients. Attention must be given to barriers to care as well as communication, coordination and relationships across the primarysecondary interface.

Keywords: communication, coordination, primary health care/standards, physician-patient relations, referral, secondary care/ standards

\section{Introduction}

High-quality primary care is characterised by accessibility, continuity, comprehensiveness, coordination and patient-centredness. ${ }^{1}$ Coordination implies the 'the ability of primary care providers to coordinate the use of other levels of health care'.2 Coordination of care can refer to coordination between different members of the primary care team, coordination with other services in the district or coordination between primary and secondary/tertiary care. Another feature is the extent of gatekeeping and to what extent patients must go through primary care to access other levels. In well-developed primary care systems primary care providers take responsibility for coordinating care for individual patients across the primary-secondary care interface.

A number of initiatives have been established to try and improve coordination of care in the Western Cape. The Vula app (https:// vula.uct.ac.za/portal) enables primary care providers to contact the specialist on call, provide patient information and receive feedback on a patient that they would like to refer as an emergency, but is not intended for outpatient referrals. Many patients are handled with advice from the specialist, while others can be quickly accepted for referral. Another system (eCCR-Electronic Continuity of Care Record) is enabling electronic in-patient discharge summaries to be created and accessed across the platform. The single patient viewer system is also trying to link patients' electronic information across levels of care by using a unique identifier. None of these initiatives, however, address the quality of referrals and feedback from outpatient visits.

In public sector primary care in the Western Cape, access to outpatient departments at hospitals is dependent on a referral and appointment system. Primary care acts as the gatekeeper to secondary care. Communication between primary care and secondary care is essential so that the outpatient department can address the key issues raised by the primary care provider and give useful and effective feedback that will guide the ongoing management of the patient in primary care.

Family physicians are the most senior clinicians supporting primary care teams within the district health services. Family physicians may be appointed at community health centres as part of the primary care team or at district hospitals where they provide regular outreach and support to the primary care team in their catchment area. ${ }^{3}$ Performing 'practical research' is part of the family physician's job description, although most family physicians struggle to do this due to their many other competing demands. The Stellenbosch University Family Physician Research Network (SUFPREN) was recently established to link busy clinicians in the health services with established researchers at the university. Family physicians can identify the key research questions and collect data within a network while primary care researchers at the university can assist with methods, analysis and report writing. The first research topic 
identified by SUFPREN was how to improve the coordination of care between primary and secondary levels.

Overall coordination of care was rated quite highly by patients, providers and managers in a recent survey in the Western Cape, with rural areas reporting significantly better scores than urban. ${ }^{4}$ The quality of feedback from specialists to primary care was, however, only one of the components measured. Family physicians are also reported to have improved coordination of care within the primary care team as well as with the referral hospitals. ${ }^{5,6}$ Family physicians may reduce the number of referrals by providing a higher level of expertise in primary care, and improve the quality of referrals through training of primary care providers as well as through closer relationships with specialists at the referral hospital. A recent observational survey of primary care consultations suggested that primary care providers have some commitment to coordination of care, although opportunities were missed in $40 \%$ of consultations. $^{7}$

Frustration with a lack of feedback from referral hospitals is a recurring theme in South African primary care. ${ }^{8,9}$ Reasons for not replying have been explored and include: lack of time and high workload, patient is deferred or does not bring the referral letter, there are no specific instructions necessary for primary care, there is no incentive for the specialist to reply as might be the case in the private sector, the referral letter is poor or illegible, the referral was unnecessary, the specialist does not think the primary care providers will understand their feedback, the specialist is going to take over management of the condition, and the reply letter will not reach the clinic anyway. Other studies, however, have shown the value of feedback in terms of improving continuity of care for the patient and capacity building of primary care providers. ${ }^{10}$ Providing a structured reply form with the referral letter has not been shown to improve feedback. ${ }^{11}$ No studies, however, have evaluated the primary-secondary care interface, in our setting, in terms of visits to hospital outpatient departments. A recent global review of the research gaps in the organisation of primary health care in low-income and middle-income countries identified that evaluating the factors related to successful referral from primary to secondary care and back was a top priority. ${ }^{12}$

The aim, therefore, was to evaluate the quality of referrals to and feedback from outpatient departments at referral hospitals within the Western Cape's primary care platform as well as patient satisfaction with the primary-secondary care interface.

\section{Methods}

\section{Study design}

A descriptive survey was undertaken.

\section{Setting}

Primary care facilities with their primary care providers (clinical nurse practitioners, medical officers and family physicians) that are supported by family physicians within SUFPREN participated in the study. The network included 15 family physicians on the service platform across four of five districts in the Western Cape. Family physicians might be employed full time in primary care at sub-districts or community health centres or district hospitals. Family physicians in district hospitals were responsible for outreach and support to their primary care facilities. Patients could be referred to their local district hospital, where they might see visiting specialists, or to regional hospitals with specialist departments or tertiary hospitals with subspecialist departments.

\section{Sample size}

Assuming a proportion of $50 \%$ of patients, $95 \%$ confidence intervals and a 5\% margin of error, a sample of 385 was required. In order to achieve this sample size each of the 15 family physicians was expected to provide data on 30 patients to give a total of 450 patients. This would enable us to achieve the sample size while allowing for some family physicians who might not provide data.

\section{Selection of patients}

All adult patients ( $>18$ years age) who had attended a referral hospital OPD appointment within the last three months were identified by primary care providers (PCP) during their consultations on days when the family physician was providing clinical care at the facility. These patients were asked to see the family physician to collect data for the study. Patients had to be seen in a primary care facility in order to collect data and the referral hospital could be a district, regional, tertiary or other specialist hospital. Patients who were referred as an emergency were excluded as well as patients who were unable to complete a questionnaire due to illness. Patients discharged after hospital admission and those sent only for an investigation that was organised directly by the PCP were also excluded.

\section{Data collection}

Data were collected from the medical record or patient if necessary on the following issues:

- quality of the referral information;

- who made the referral (nurse practitioner, medical officer, family physician, other);

- where was the patient referred (name of facility and discipline);

- what was the reason for referral;

- quality of the feedback information;

- source of the feedback information (letter, information technology, patient, other);

- did the feedback make a difference to clinical care at this visit.

The quality of written referral and feedback letters was judged according to a list of criteria that were constructed and validated by the family physicians in SUFPREN. The primary researcher constructed a list of criteria from the literature ${ }^{13}$ and the content and construct of this list were then validated with the network of family physicians through email and a workshop. Each criterion was judged as present, not present or not applicable (Supplementary file A). The criteria selected can also be seen in Tables 3 and 6 of the results section. The data collection tool was piloted prior to use to ensure it was understandable and practical.

A brief questionnaire was also administered face-to-face with each patient on their satisfaction with the referral and feedback (Supplementary file B). The closed and open questions were again designed and validated by the family physicians in SUFPREN. The questionnaire was also piloted prior to use.

\section{Data analysis}

Data was captured on an Excel spreadsheet (Microsoft Corp, Redmond, WA, USA) and checked for errors or omissions. 
Data were analysed using the Statistical Package for Social Sciences version 25 (IBM Corp, Armonk, NY, USA). Categorical data were reported as frequencies and percentages, while scale data were reported as means and standard deviations or if not normally distributed as medians and interquartile ranges. Qualitative data, from the questionnaire's open questions, were captured verbatim in Excel, categorised thematically and the frequencies of different categories of response calculated.

A total percentage score was calculated (Yes $=1$ and $\mathrm{No}=0$ ) for the quality of each referral (19 items) and feedback (12 items) letter and the denominator adjusted if the item was not applicable. The median percentage score for the referral letters was then compared with the district of origin and type of referring practitioner using a non-parametric Kruskal-Wallis test. Similarly, the score for the feedback letter was compared with the level of hospital and type of discipline.

\section{Ethical considerations}

The study was approved by the Health Research Ethics Committee at Stellenbosch University (N18/02/014) and permission was granted by the Department of Health to conduct the study.

\section{Results}

Data were obtained by 7 family physicians from 141 patients, 58 (41.1\%) male and 83 (58.9\%) female, with a mean age of 51.3 years (SD 15.7). Patients came from a variety of primary care facilities, in different districts, were referred by a variety of practitioners and for different reasons as shown in Table 1. Patients came from both metropolitan (46.1\%) and rural areas (53.9\%).

Table 1: Characteristics of primary care facilities $(n=141)$

\begin{tabular}{lc}
\hline Variables & $n(\%)$ \\
\hline Location of primary care facility: & $65(46.1)$ \\
\hline Metropole & $22(15.6)$ \\
\hline West Coast & $30(21.3)$ \\
\hline Cape Winelands & $0(0.0)$ \\
\hline Overberg & $24(17.0)$ \\
\hline Garden Route & \\
\hline Who made the appointment: & $48(34.0)$ \\
\hline Family physician & $50(35.5)$ \\
\hline Medical officer & $17(12.3)$ \\
\hline Community service medical officer & $2(1.4)$ \\
\hline Intern & $2(1.4)$ \\
\hline Clinical nurse practitioner & $16(11.6)$ \\
\hline Referral hospital doctor & $3(2.1)$ \\
\hline Private practitioner & $3(2.1)$ \\
\hline Unknown & \\
\hline Reasons for referral:* & $29(20.6)$ \\
\hline Not sure of diagnosis & $43(30.5)$ \\
\hline Not sure of treatment & $50(35.5)$ \\
\hline Need for special investigation & $72(51.1)$ \\
\hline Need for additional management & $18(12.8)$ \\
\hline Other & $2.8)$ \\
\hline
\end{tabular}

*More than one reason can apply per referral.
Table 2: Characteristics of referral hospitals $(n=141)$

\begin{tabular}{lc}
\hline Variables & $\boldsymbol{n}(\%)$ \\
\hline Level of hospital where patient seen: & \\
\hline District hospital & $25(17.7)$ \\
\hline Regional hospital & $40(28.4)$ \\
\hline Tertiary hospital & $72(51.1)$ \\
\hline Other & $4(2.8)$ \\
Type of discipline referred to: & \\
\hline Internal medicine & $37(26.2)$ \\
\hline Medical sub-specialities & $35(24.8)$ \\
\hline Surgery & $9(6.4)$ \\
\hline Surgical sub-specialities & $29(20.6)$ \\
\hline Gynaecology & $12(8.5)$ \\
\hline Orthopaedics & $9(6.4)$ \\
\hline Psychiatry & $2(1.4)$ \\
\hline Paediatrics & $2(1.4)$ \\
\hline Family medicine & $1(0.7)$ \\
\hline Unknown & $5(3.5)$ \\
\hline
\end{tabular}

Patients were referred to different types of hospitals and different disciplines as shown in Table 2. Those referred to district hospitals could have been seeing specialists doing outreach clinics.

Table 3 presents results on the information given in the referral letter. A copy of the referral letter was available in $99(70.7 \%)$ of patients, not applicable in $19(13.6 \%)$ and not available in 22 (15.7\%). Referral letters from primary care providers (> 90\%) were legible, respectful, provided patient and provider identifiers and stated the reason for referral as well as the patient's history. In most cases (80-89\%) they also stated the provider's assessment, examination findings and the patient's past medical history. They were less (50-79\%) likely to describe the

Table 3: Quality of the referral letter $(n=99)$

\begin{tabular}{ll}
\hline Variables & $n(\%)$ \\
\hline Is the whole letter legible and easy to read? & $98(99.0)$ \\
\hline Is the letter respectful and collegial? & $97(98.0)$ \\
\hline Is the patient's name stated? & $97(98.0)$ \\
\hline Is the patient's folder number stated? & $96(97.0)$ \\
\hline Is the date the letter was written stated? & $96(97.0)$ \\
\hline Is the practitioner's name stated (not just signature)? & $89(89.9)$ \\
\hline Is the practitioner's contact number stated? & $42(42.4)$ \\
\hline $\begin{array}{l}\text { Is the reason for referral clearly stated (what is expected of } \\
\text { the OPD)? }\end{array}$ & $90(90.9)$ \\
\hline Is the practitioner's assessment or diagnosis stated? & $87(87.9)$ \\
\hline Is the patient's history described? & $94(94.9)$ \\
\hline Are the clinical examination findings described? & $82(82.8)$ \\
\hline Are the results of side room tests or investigations stated? & $79(79.8)$ \\
\hline Is any treatment for the problem described? & $68(68.7)$ \\
\hline Is the patient's usual prescription listed? & $54(54.5)$ \\
\hline Is the patient's past medical history stated? & $88(88.9)$ \\
\hline Is the presence or absence of allergies stated? & $11(11.1)$ \\
\hline $\begin{array}{l}\text { Are any lifestyle factors noted (e.g. smoking tobacco, alcohol } \\
\text { intake)? }\end{array}$ & $31(31.3)$ \\
\hline $\begin{array}{l}\text { Does the letter contain any individual information (e.g. what } \\
\text { has been said to patient, patient's perspective)? }\end{array}$ & $20(20.2)$ \\
\hline $\begin{array}{l}\text { Does the letter contain any other contextual information (e.g. } \\
\text { family, household, housing, occupation, income, grants)? }\end{array}$ & $30(30.3)$ \\
\hline
\end{tabular}


Table 4: Patients' feedback on their experience of being referred at primary care facility $(n=83)$

\begin{tabular}{|c|c|c|}
\hline Variable & $n(\%)$ & Quotations \\
\hline No problems with process & $57(68.7)$ & $\begin{array}{l}\text { 'Everything went very well, the doctor helped me very much.' } \\
\text { 'Patient is satisfied with service. His referral letter was done in May and he got an appointment for } \\
\text { June.' } \\
\text { 'Because they consulted with the family physician, patient got the gastroscopy and respiratory } \\
\text { appointment the same day. Very happy about this.' }\end{array}$ \\
\hline $\begin{array}{l}\text { Improve process of obtaining the } \\
\text { appointment date }\end{array}$ & $14(16.9)$ & $\begin{array}{l}\text { 'Took very long to get appointment ( } 6 \text { months). Doctors had to phone multiple times to get an } \\
\text { appointment. Would like to be given an appointment on the day of referral for a date appropriate in } \\
\text { the future.' } \\
\text { 'Was referred multiple times by fax without getting an appointment with a date on the day of referral } \\
\text { from primary care.' } \\
\text { 'Letter to neurology was send via the clerk. No appointment date in months.' } \\
\text { 'Letter done and faxed but she never had appointment. Do not feel fax system awaiting } \\
\text { appointments work well.' }\end{array}$ \\
\hline $\begin{array}{l}\text { Provide appointment date via } \\
\text { information technology }\end{array}$ & $6(7.2)$ & $\begin{array}{l}\text { 'Send them SMS on the phone because sometime we lose the card they give us.' } \\
\text { 'Use of social media e.g. WhatsApp.' } \\
\text { 'Use e-mail.' }\end{array}$ \\
\hline
\end{tabular}

results of investigations in primary care, treatment given and the usual prescription. They did not usually $(<50 \%)$ state allergies, the provider's contact details, relevant lifestyle and contextual issues, or provide any pertinent information about the patient's perspective on their illness.

Table 4 categorises patients' feedback on their experience of being referred at the primary care facility. Most patients agreed that the referral was necessary, understood why they were referred and were happy with the administrative process. Some were unhappy with the length of time taken to obtain the appointment date. It appeared that some specialist departments had inefficient systems in place to screen and respond to requests for appointments. A few patients would have liked to receive the appointment date by text message or other electronic means of communication and to have an earlier appointment date.

Table 5 provides information on the nature of feedback from the referral hospital. Written feedback was available in only $57.4 \%$ of patients. In $31.9 \%$ of patients, doctors had to spend time obtaining feedback and in over half of cases the patient (52.5\%) was

Table 5: Nature of feedback from hospital $(n=141)$

\begin{tabular}{lc}
\hline Variable & $\boldsymbol{n}(\%)$ \\
\hline $\begin{array}{l}\text { Did the hospital provide feedback to the primary care } \\
\text { provider? }\end{array}$ & $81(57.4)$ \\
\hline $\begin{array}{l}\text { Did the primary care provider spend time obtaining } \\
\text { feedback? }\end{array}$ & $45(31.9)$ \\
\hline What was the source of information? & $55(39.0)$ \\
\hline Letter & $8(5.7)$ \\
\hline Telephone & $73(52.5)$ \\
\hline $\begin{array}{l}\text { Patient } \\
\text { Information technology, e.g. ECM, ECCR, email }\end{array}$ & $24(16.9)$ \\
\hline Prescription & $21(14.9)$ \\
\hline Copy of hospital notes/folder & $8(5.6)$ \\
\hline Results of investigations & $2(1.4)$ \\
\hline Did feedback influence the management plan at this visit? & $77(54.6)$ \\
\hline
\end{tabular}

the source of information on what happened. Feedback only influenced management in that consultation in $54.6 \%$ of patients.

Table 6 provides information on the quality of written feedback from the referral hospital. Feedback from the hospital (>90\%) was legible, identified the patient and specialist, stated the assessment and recommended management plan. In most cases (80-89\%) the feedback was respectful and addressed the reason for referral. They were less likely $(50-79 \%)$ to provide contact details, give the results of investigations or procedures, clarify what should happen now in primary care or whether the hospital was still involved in the patient's care.

Table 7 provides feedback from patients on their experience of the OPD visit at the referral hospital. Less than half of the patients were satisfied with their hospital visit and had problems with transport to the hospital, the time spent waiting and queuing as well as the organisation of the visit. A few patients

Table 6: Quality of written feedback from referral hospital $(n=81)$

\begin{tabular}{|c|c|}
\hline Variables & $n(\%)$ \\
\hline Is all the written feedback legible and easy to read? & $80(98.8)$ \\
\hline Is the feedback respectful and collegial? & $65(80.2)$ \\
\hline Is the patient's identity clearly stated? & $81(100.0)$ \\
\hline Is the date on which they were seen clearly stated? & $81(100.0)$ \\
\hline $\begin{array}{l}\text { Is the hospital practitioner's identity stated (not just } \\
\text { signature)? }\end{array}$ & $75(92.6)$ \\
\hline Are the hospital practitioner's contact details stated? & $50(61.7)$ \\
\hline Has the reason(s) for referral been addressed? & $69(85.2)$ \\
\hline Is the hospital's assessment or diagnosis stated? & $80(98.8)$ \\
\hline $\begin{array}{l}\text { Is the hospital's recommended management or } \\
\text { prescription stated? }\end{array}$ & $81(100.0)$ \\
\hline Are the results of any investigations or procedures stated? & $48(59.2)$ \\
\hline $\begin{array}{l}\text { Are instructions given regarding ongoing primary care (i.e. } \\
\text { what the primary care provider should do going forward)? }\end{array}$ & $56(69.1)$ \\
\hline $\begin{array}{l}\text { Is the further role of the hospital clear (i.e. patient } \\
\text { discharged, to be seen again)? }\end{array}$ & $51(62.9)$ \\
\hline
\end{tabular}


Table 7: Patients' feedback on their visit to OPD at the referral hospital $(n=89)$

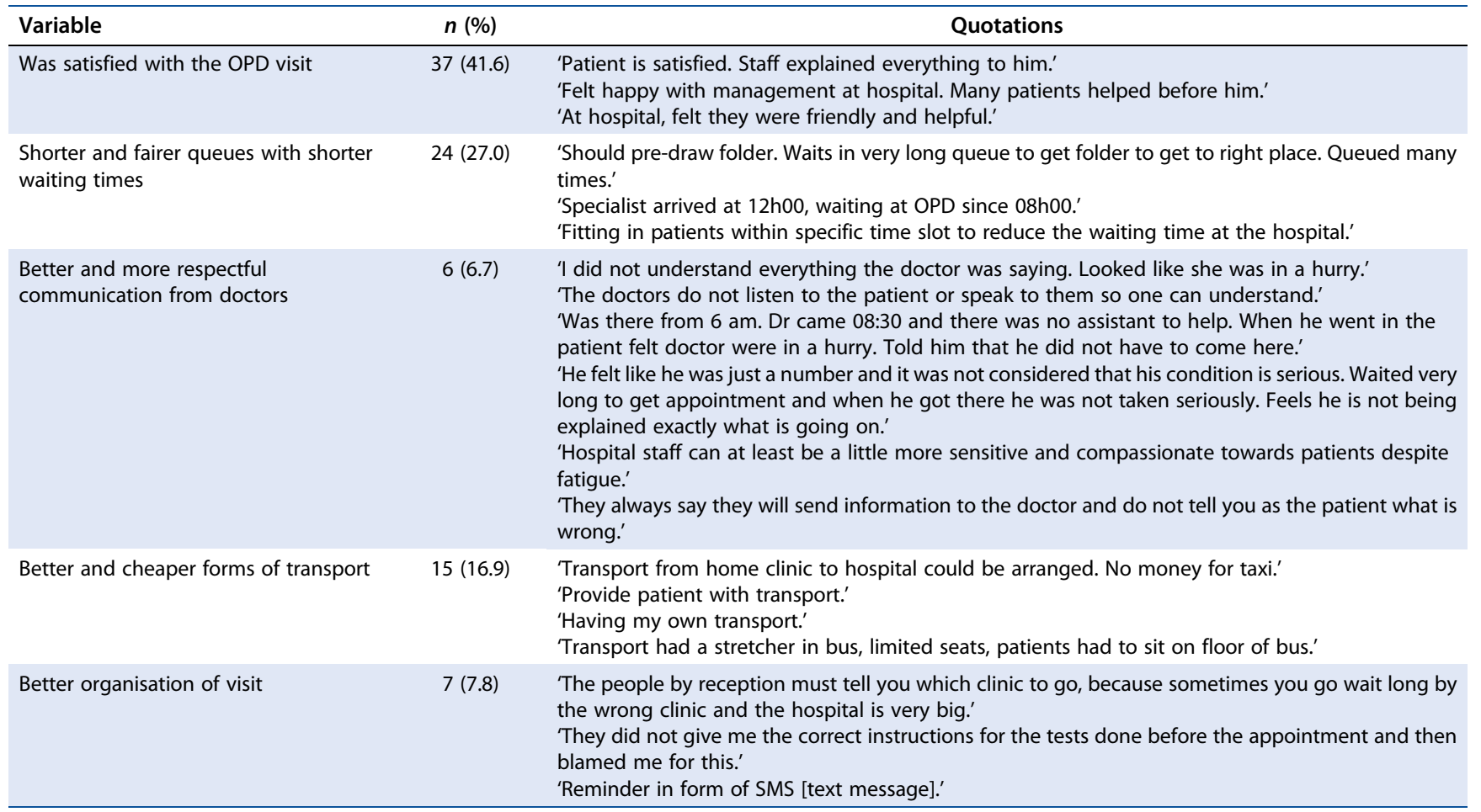

struggled to understand the consultant and felt that the doctor was rushed, disinterested or insensitive.

Table 8 presents the patients' perspective on key aspects of their visit to the OPD. Patients reported that the reason for referral was not addressed in $26 \%$ of visits and their questions were not answered in $29 \%$ of visits. Although the commonest source of feedback in primary care was the patients themselves, many did not know what the hospital doctor thought was wrong (36\%), and did not know what treatment was recommended $(27 \%)$ or the results of tests $(33 \%)$ and procedures (29\%).

Table 8: Agreement of patients with statements regarding key aspects of their OPD visit

\begin{tabular}{|c|c|}
\hline Variable & $\begin{array}{l}\text { Fully agree } n \\
(\%)\end{array}$ \\
\hline $\begin{array}{l}\text { I needed to be referred to the hospital outpatients ( } n \\
=98 \text { ) }\end{array}$ & $95(96.9)$ \\
\hline $\begin{array}{l}\text { I know why I was referred to the hospital outpatients } \\
(n=98)\end{array}$ & $92(93.9)$ \\
\hline $\begin{array}{l}\text { At the end of the visit I knew what the hospital doctor } \\
\text { thought was wrong with me }(n=98)\end{array}$ & $63(64.3)$ \\
\hline $\begin{array}{l}\text { The hospital doctor addressed the reason for my } \\
\text { referral }(n=96)\end{array}$ & $71(74.0)$ \\
\hline $\begin{array}{l}\text { I know what treatment the hospital doctor } \\
\text { recommended }(n=97)\end{array}$ & $71(73.2)$ \\
\hline I know the results of my tests at the hospital $(n=87)$ & $58(66.7)$ \\
\hline $\begin{array}{l}\text { I know what operations or procedures were done at } \\
\text { the hospital }(n=59)\end{array}$ & $42(71.2)$ \\
\hline I know if I need to go back to the hospital $(n=97)$ & $79(81.4)$ \\
\hline $\begin{array}{l}\text { The hospital doctor answered any questions that I had } \\
(n=92)\end{array}$ & $65(70.7)$ \\
\hline $\begin{array}{l}\text { The hospital doctor explained what the clinic needs to } \\
\text { do now }(n=96)\end{array}$ & $51(53.1)$ \\
\hline
\end{tabular}

Table 9 looks at the relationship between the quality of the referral or feedback letters and key factors. There was a significant difference between districts and types of practitioners making the referral. Family physicians wrote the best referrals, followed by junior medical officers, established medical officers and lastly nurses. There was also a significant difference between feedback from different levels of hospital, with district hospitals providing a higher quality of feedback. Tertiary hospitals also appeared to

Table 9: Factors related to the quality of written referrals and feedback.

\begin{tabular}{lcc}
\hline Variable & $\begin{array}{c}\text { Median percentage score } \\
\text { Median \% (95\% Cl) }\end{array}$ & $\begin{array}{c}p \text { - } \\
\text { value }\end{array}$ \\
\hline District responsible for the referral letter: & \\
\hline Cape Winelands & $70.6(47.4-93.7)$ & $<0.001$ \\
Garden Route & $89.5(89.5-94.7)$ & \\
West Coast & $61.1(57.9-68.4)$ & \\
Metropole & $68.4(68.4-73.7)$ & $<0.001$ \\
Practitioner responsible for the referral letter: & \\
Nurses & $57.9(-)$ & \\
Junior medical officers & $68.4(68.4-79.0)$ & \\
Medical officers & $63.2(61.1-68.4)$ & \\
Family physicians & $84.2(84.2-89.5)$ & \\
Level of hospital giving feedback: & & \\
District hospital & $91.7(91.7-100.0)$ & \\
Regional hospital & $75.0(72.7-91.0)$ & \\
Tertiary hospital & $87.1(75.0-91.7)$ & \\
\hline Type of discipline giving feedback: & & \\
Medicine & $90.9(83.3-91.7)$ & \\
Surgery & $75.0(72.7-91.7)$ & \\
Obstetrics and gynaecology & $90.0(75.0-100.0)$ & \\
Psychiatry & $80.0(-)$ & \\
Other & $82.6(81.8-83.3)$ & \\
\hline & & \\
\hline
\end{tabular}


provide better feedback than regional hospitals. There was no difference in the quality of feedback between hospital specialists.

\section{Discussion}

The findings of this study are discussed in terms of barriers to care, communication, coordination and relationships as suggested by a recent systematic review of the primary-secondary care interface. ${ }^{14}$

\section{Barriers to care}

Barriers to care included problems with the system for obtaining appointments and long waiting times at the referral hospital. The complexity of appointment systems and bureaucracy involved can make patients feel disempowered and stressed. ${ }^{14}$ The public sector primary care services in South Africa are meant to act as gatekeepers to the hospital specialists. In other countries with gatekeeping, patients have found that access to their PCPs and the knowledge of their PCPs were barriers to care. ${ }^{14}$ Although not noted in this study, first contact access to PCPs and their expertise have been identified as issues elsewhere. ${ }^{7,15}$ Transport came through as a major barrier to care in this study, but was not mentioned in the systematic review.

\section{Communication issues}

Poor communication was an issue for some patients and language barriers, poor staff attitudes and lack of time were seen as contributing factors. Referrals demonstrated a lack of a patient-centred and holistic approach in primary care, which has been recognised elsewhere. ${ }^{13}$ Improving patient-centredness is a key goal of our health services and is also seen as a key issue for the primary-secondary care interface. ${ }^{14}$ Other studies have noted that poor communication can lead to passivity, anxiety and uncertainty in the patient or attempts to be more proactive through involving family members, making lists of questions or arguing with the healthcare staff. ${ }^{14}$ One had the impression from the study findings that our patients tend to be more passive and mostly suffer in silence.

Transfer of information across the primary-secondary interface was an issue with no referral letter found in $16 \%$ of patients and no written feedback found in $61 \%$ of patients. Family physicians with postgraduate training and recently qualified junior medical officers wrote the best referrals. It was not possible to determine why districts differed in the quality of referrals, although the Garden Route was a pilot district for national health insurance and had strong outreach, with family medicine, from the hospitals to the primary care services.

Older primary care doctors may be more likely to write a referral letter, ${ }^{13}$ while hospital specialists are more likely to reply if they receive the referral letter, know or trust the primary care doctor, and if they recognise the coordinating role of primary care. This could explain why district hospitals, which were closer to the PCPs, gave better feedback. Patients may fail to deliver both the referral letter and the feedback. Other reasons for poor transfer of information include a negative attitude that 'doesn't think it is necessary, lacks interest or can't be bothered' and a lack of time. ${ }^{13}$ Hospital specialists may also defer giving feedback if they are going to see the patient again, although this creates uncertainty for the primary care provider and thus suboptimal coordination and continuity of care. High workload and insufficient resources in both primary and secondary care can act as a barrier to communication ${ }^{16}$ and these issues are widespread within the South African health system and were mentioned in the qualitative data.

\section{Coordination of care}

Feedback did not seem to recognise the important role of primary care in coordination and continuity of care. Poor feedback and using the patient him/herself as a major source of information is likely to lead to delays in care, inaccurate care and frustration for the patient and primary care provider. Primary care providers have a high patient load ${ }^{17}$ and cannot afford to spend time searching for feedback. Primary care in South Africa does not yet use electronic medical records, which have been recognised elsewhere as an important contributor to effective coordination of care. ${ }^{16}$

South African primary care is weak in terms of relational continuity of care, ${ }^{15}$ which itself is important for ongoing coordination of care for individual patients. One suspects that neither the hospital specialists nor the primary care providers conceptualise primary care providers as formally taking responsibility for such continuity and coordination. Some individual providers spent time trying to improve coordination of care, but still relied mostly on the patient when communication was absent. More informal communication channels between practitioners may improve coordination (for example email or WhatsApp), ${ }^{16}$ but such contact details were largely absent from written communication. Again, patients may play a role in coordinating care and their roles have been described as largely passive or proactive. ${ }^{14}$ There was little evidence of patients proactively improving coordination in this study.

\section{Relationships}

Three relationships were seen as important. The patient's relationship with (a) the primary care provider and (b) the hospital specialist, and the relationship between the primary care provider and hospital specialist. A lack of continuity in the relationship with the primary care provider may reduce patients' confidence and trust. ${ }^{14}$ At the hospital some patients felt lost in the system and not being valued may increase a sense of powerlessness and frustration. The relationship across the primarysecondary interface has been characterised as one of professional tribalism. ${ }^{14}$ Such tribalism can lead to something of a disrespectful and confrontational relationship, although a commitment to professionalism and better patient care can overcome the divide.

Very few referrals were made by nurse practitioners as they tend to refer internally to primary care doctors and these doctors then make referrals to hospital specialists. The majority of referrals (51\%) were to internal medicine and its subspecialties. This could represent the burden of disease, but consideration should be given as to whether this reflects learning needs for primary care doctors.

\section{Limitations}

Patients were selected for the study by the family physician and this may have introduced a selection bias towards patients referred by them. Patients were selected across the whole of the Western Cape and from all districts apart from the Overberg. The family physicians in the Overberg did not participate in SUFPREN and this could have impacted the results. Overberg shares similar characteristics and referral pathways, however, to the Cape Winelands. 
Family physicians working in secondary-level hospitals struggled to recruit patients from the primary care platform and this limited the sample size. The sample size was much smaller than expected $(141 / 385,37 \%)$ and this will have increased the margin of error around the measurements. The sample of 141 was sufficient to measure a proportion of $70 \%$ with $95 \%$ confidence intervals and $7.5 \%$ margin of error.

\section{Recommendations}

Recommendations that can be made from this study relate to the four areas discussed above:

- Systems issues that act as barriers to care should be addressed. In particular the screening of referrals and provision of an appointment date should be streamlined, and cell phone technology rather than fax could be used to improve communication. While partly outside the control of health services there is a need to improve transport to referral hospitals.

- Transfer of information should be improved, particularly feedback from the referral hospitals that not only provides information on the visit but supports ongoing and further coordination of care by the primary care provider. Again, there is an opportunity for information technology to streamline both referral and feedback. The Vula app has shown what is possible in terms of emergency referrals across the primary-secondary interface.

- PCPs should be trained and capacitated to take on a more formal role of coordinating patient care across the primary-secondary interface and all the role players should support this important function. A commitment to improved relational continuity of primary care should also improve coordination.

- Efforts should continue among all health professionals to improve patient-centred relationships. Interaction between primary and secondary level practitioners should break down any sense of tribalism and foster mutual respect, sharing of information, professionalism and a shared vision of improving patient care. Forums can be created at the district or substructure level to enable interaction between practitioners. Relationships may be better with the district hospital than with the more distant regional and tertiary hospitals. Educational interventions using small groups of primary and secondary care practitioners have shown promise in changing behaviour and improving communication. ${ }^{18}$

\section{Conclusion}

Most patients had an appropriate referral letter, although these were biomedical and lacked a holistic description of the patient. Written feedback was available in less than half of patients and the patient was the main source of information on the hospital visit. The issues identified regarding the primary-secondary care interface for outpatient referrals can be categorised into barriers to care, communication, coordination and relationship issues. Recommendations are made to improve performance in each of these areas.

Acknowledgements - The research question was chosen by the whole Stellenbosch University Family Physician Research Network, who also commented on the initial analysis at a workshop in May 2019. Thanks are extended to Ms Marianna James who captured the data and provided administrative support. Funds were provided by the Division of Family Medicine and Primary Care, Stellenbosch University.
Disclosure statement - No potential conflict of interest was reported by the authors.

Supplemental data - Supplemental data for this article can be accessed at https://doi.org/10.1080/20786190.2019.1676021 description of location.

\section{ORCID}

Robert Mash (D) http://orcid.org/0000-0001-7373-0774

Klaus von Pressentin (D) http://orcid.org/0000-0001-5965-9721

\section{References}

1. Primary Health Care Performance Initiative [Internet]. [cited 2018 Apr 18]. Available from: https://phcperformanceinitiative.org/

2. Kringos DS, Boerma WG, Hutchinson A, van der Zee J, Groenewegen PP. The breadth of primary care: a systematic literature review of its core dimensions. BMC Health Serv Res. NIVEL-Netherlands Institute for Health Services Research, Otterstraat 114-8, 3500 BN Utrecht, the Netherlands. d.kringos@nivel.nl; 2010 Mar 13;10:65.

3. Mash R, Ogunbanjo G, Naidoo SS, et al. The contribution of family physicians to district health services: a national position paper for South Africa. South African Fam Pract. 2015;57(3):54-61.

4. Bresick GF, Sayed A-R, Le Grange C, et al. Western Cape Primary Care Assessment Tool (PCAT) study: measuring primary care organisation and performance in the Western Cape Province, South Africa (2013). African J Prim Heal Care Fam Med [Internet]. AOSIS Publishing; 2016 May 19;8(1):1-12. [cited 2018 Oct 10]. Available from: https://phcfm. org/index.php/phcfm/article/view/1057.

5. Swanepoel M, Mash B, Naledi T. Assessment of the impact of family physicians in the district health system of the Western Cape, South Africa. African J Prim Heal Care Fam Med. 2014;6(1).

6. Von Pressentin K, Mash R, Baldwin-Ragaven L, et al. The bird's-eye perspective: how do district health managers experience the impact of family physicians within the South African district health system? A qualitative study. South African Fam Pract [Internet]. Taylor \& Francis; 2018 Jan 23;60(1):13-20. [cited 2018 Apr 5]. Available from: https://www.tandfonline.com/doi/full/10.1080/ 20786190.2017.1348047.

7. Christoffels R, Mash B. How well do public sector primary care providers function as medical generalists in Cape Town: a descriptive survey. BMC Fam Pract [Internet]. 2018 Dec 19;19(1):122. [cited 2019 May 10]. Available from: https://bmcfampract.biomedcentral. com/articles/10.1186/s12875-018-0802-x.

8. Couper I. Referral letters and replies: can we do better? S Afr Fam Pr. 1998;19(3):90-91.

9. Smith $\mathrm{S}$, Khutoane $\mathrm{G}$. Why doctors do not answer referral letters. South African Fam Pract [Internet]. 2009 Mar 15;51(2):168-168. [cited 2019 Jul 15]. Available from: https://www.tandfonline.com/ doi/full/10.1080/20786204.2009.10873836.

10. Gagliardi A. Use of referral reply letters for continuing medical education: a review. J Contin Educ Health Prof [Internet]. John Wiley \& Sons, Ltd; 2002;22(4):222-9. [cited 2019 Jul 15]. Available from: http://content.wkhealth.com/linkback/openurl?sid=WKPTLP: landingpage\&an=00005141-200222040-00005.

11. Ramanayake RPJC, Sumanasekera RDN, Athukorala LACL, et al. Referral letter with an attached structured reply form: Is it a solution for not getting replies. J Fam Med Prim Care [Internet]. Wolters Kluwer Medknow Publications; 2013;2(4):319. [cited 2019 Jul 15]. Available from: http://www.jfmpc.com/text.asp?2013/2/4/319/123777.

12. Goodyear-Smith F, Bazemore A, Coffman M, et al. Research gaps in the organisation of primary healthcare in low-income and middleincome countries and ways to address them: a mixed-methods approach. BMJ Glob Heal [Internet]. BMJ Specialist Journals; 2019 Aug 16;4(Suppl 8):e001482. [cited 2019 Aug 26]. Available from: http://gh.bmj.com/lookup/doi/10.1136/bmjgh-2019-001482.

13. Vargas I, Garcia-Subirats I, Mogollón-Pérez A-S, et al. Understanding communication breakdown in the outpatient referral process in Latin America: a cross-sectional study on the use of clinical correspondence in public healthcare networks of six countries. Health Policy Plan [Internet]. Narnia; 2018 May 1;33(4):494-504. [cited 
2019 Jul 15]. Available from: https://academic.oup.com/heapol/ article/33/4/494/4857369.

14. Sampson R, Cooper J, Barbour R, Polson R, Wilson P. Patients' perspectives on the medical primary-secondary care interface: systematic review and synthesis of qualitative research. BMJ Open [Internet]. British Medical Journal Publishing Group; 2015 Oct 1;5(10):e008708. [cited 2019 Jul 15]. Available from: https://bmjopen.bmj.com/ content/5/10/e008708

15. Bresick G, von Pressentin KB, Mash R. Evaluating the performance of South African primary care: a cross-sectional descriptive survey. South African Fam Pract [Internet]. Taylor \& Francis; 2019 May 4;61 (3):109-16. [cited 2019 Jul 15]. Available from: https://www. tandfonline.com/doi/full/10.1080/20786190.2019.1596666

16. Waibel S, Vargas I, Aller M-B, et al. Continuity of clinical management and information across care levels: perceptions of users of different healthcare areas in the Catalan national health system. BMC Health Serv Res [Internet]. Bio Med Central; 2016 Dec 2;16(1):466. [cited 2019 Jul 15]. Available from: http://bmchealthservres. biomedcentral.com/articles/10.1186/s12913-016-1696-8.

17. Healthcare 2030: the road to wellnes [Internet]. Cape Town: Western Cape Government Health; 2014. Available from: https://www. westerncape.gov.za/assets/departments/health/healthcare2030.pdf

18. Sampson R, MacVicar R, Wilson P. Improving the primary-secondary care interface in Scotland: a qualitative exploration of impact on clinicians of an educational complex intervention. BMJ Open [Internet]. British Medical Journal Publishing Group; 2017 Jun 26 7(6): e016593. [cited 2019 Jul 15]. Available from: http://www.ncbi.nlm. nih.gov/pubmed/28652293.

Received: 16-07-2019 Accepted: 1-10-2019 